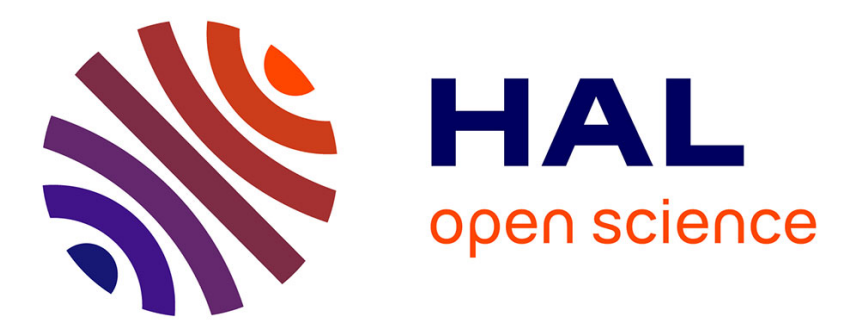

\title{
Chromenes involving a two-photon absorbing moiety: photochromism via intramolecular resonance energy transfer
}

Laura Bekere, Vladimir Lokshin, Mark Sigalov, Raz Gvishi, Peng Zhao, David Hagan, Eric van Stryland, Vladimir Khodorkovsky

\section{To cite this version:}

Laura Bekere, Vladimir Lokshin, Mark Sigalov, Raz Gvishi, Peng Zhao, et al.. Chromenes involving a two-photon absorbing moiety: photochromism via intramolecular resonance energy transfer. New Journal of Chemistry, 2016, 40 (2), pp.1143-1148. 10.1039/C5NJ02490K . hal-03500747

\section{HAL Id: hal-03500747 https://hal.science/hal-03500747}

Submitted on 12 Jan 2022

HAL is a multi-disciplinary open access archive for the deposit and dissemination of scientific research documents, whether they are published or not. The documents may come from teaching and research institutions in France or abroad, or from public or private research centers.
L'archive ouverte pluridisciplinaire HAL, est destinée au dépôt et à la diffusion de documents scientifiques de niveau recherche, publiés ou non, émanant des établissements d'enseignement et de recherche français ou étrangers, des laboratoires publics ou privés. 


\section{Chromenes involving a two-photon absorbing moiety: photochromism via intramolecular resonance energy transfert}

Received 00th January 20xx Accepted 00th January $20 x x$

DOI: $10.1039 / x 0 x \times 00000 x$
L. Bekere, ${ }^{a}$ V. Lokshin, ${ }^{a}$ M. Sigalov, ${ }^{\text {b }}$ R. Gvishi, ${ }^{c}$ P. Zhao, ${ }^{d}$ D. J. Hagan, ${ }^{d}$ E. W. Van Stryland, ${ }^{d}$ and V. Khodorkovsky ${ }^{\mathrm{a}, *}$

www.rsc.org/

\begin{abstract}
New derivatives involving the photochromic $2 \mathrm{H}$ benzo[h]chromene moieties covalently linked to the $2,7-$ bis(carbazolyl)fluorene-derived two-photon absorbing moiety were designed to enable the possibility of resonance energy transfer from the fluorene donor to the photochromic acceptor. Rapid coloration of colorless solutions was observed upon oneand two-photon absorption.
\end{abstract}

Photochromism, defined as a reversible transformation of chemical species, induced in one or both directions by electromagnetic radiation ${ }^{1}$ attracts considerable interest owing to the potential use of this phenomenon in various applications. Among such applications, the development of optical data storage materials, ${ }^{2}$ optical limiting ${ }^{3}$, and manipulating supramolecular self-assemblies ${ }^{4}$ should be mentioned. Using two-photon absorption (2PA) instead of one-photon absorption for inducing photochromic transformations offers further advantages and opens new possibilities in data recording and biomedical applications. ${ }^{5}$

Most of the known organic photochromes possess very small 2PA cross section values and the multiphoton-induced photochromic phenomena can be observed in solid state ${ }^{6}$ or in polymer matrix containing $1.3 \mathrm{M}$ of a photochromic material in the presence of gold nanoparticles ${ }^{7}$. Rendering large 2PA cross sections by chemical modification of the photochrome structure, such as attaching a molecule with the large 2PA cross section, is difficult to achieve, as the resulting molecule may exhibit weaker photochromic response or even lose the photochromic properties ${ }^{8}$. Porphyrin-perinaphthothioindigo and azo conjugates can be mentioned as a successful realization of this approach, ${ }^{9,10}$ for a recent review see ${ }^{11}$.

\footnotetext{
aix Marseille Université, CNRS, CINaM UMR 7325, 13288, Marseille, France. Email: khodor@cinam.univ-mrs.fr.

bepartment of Chemistry, Ben-Gurion University of the Negev, Beer Sheva, 84105, Israel.

c. Applied Physics Division, Soreq NRC, Yavne 81800, Israel.

CREOL, The College of Optics and Photonics, University of Central Florida Orlando, FL 32816, USA.

+ Electronic Supplementary Information (ESI) available: Experimental instrumentation, procedures and new compounds characterization. See DOI: $10.1039 / \mathrm{x} 0 \times x \times 0000 \mathrm{x}$
}

An alternative approach involves resonance energy transfer (RET) from a 2PA fluorophore as a donor to a photochrome as an acceptor. Previously, we demonstrated that a mixture of a fluorophore and a spiroxazine-derived photochrome absorbs two photons and exhibits RET. ${ }^{12} \mathrm{~A}$ twofold enhancement in the rate of the photochromic conversion of a diarylethene-derived photochrome in the presence of 2 photon absorbing fluorenes was also demonstrated. ${ }^{13}$

Because of the strong dependence of RET efficiency on donor-acceptor separation, effective RET between separate molecules requires high concentrations of the components and is best suitable for aggregates or polymers. ${ }^{14}$ This concentration requirement can be removed when the acceptor and donor are chemically linked. Several derivatives involving both a photochromic and a fluorescent moiety have been reported, targeting fluorescence switching using the RET phenomenon. In this case, however, the colored (open) forms of the photochromes played the role of energy donors, see for instance. ${ }^{15}$ Diarylethenes were demonstrated to be the most suitable candidates as 2PA switching molecules so far, although their direct conjugation with the 2PA moiety can lead to relatively low 2PA cross section values. ${ }^{16}$

Here we report on the synthesis of a series of new bifunctional molecules involving the 2,7bis(carbazolyl)fluorene-derived 2PA moiety covalently linked by the $\left(\mathrm{CH}_{2}\right)_{3}$ bridge to the chromene-derived photochromic moiety $(\mathbf{1} \mathbf{a}-\mathbf{3 a})$ along with the model derivatives lacking the 2PA fragment (1) - 3b) and give an account of their spectroscopic behavior in solution.

The structures of $2 \mathrm{H}$-benzo[ $h]$ chromene (2H-naphtho[1,2b] pyran) derivatives $\mathbf{1} \mathbf{-} \mathbf{3}$ are shown in Fig. 1 . These derivatives were designed so that the longest wavelength absorption of the photochromic moiety overlaps with the fluorescence band of 9,9'-(9-(3-hydroxypropyl)-9-methyl-9H-fluorene-2,7-diyl)bis$9 H$-carbazole, and the distance between the photochromic and the 2PA moieties is about $5-6 \AA$ to provide efficient RET and to exclude the possibility of through-bond and through-space intermolecular electronic interaction (This distance is calculated from the B3LYP/6-31G(d) geometry optimization. A 
detailed account of DFT calculations on derivatives $\mathbf{1}-\mathbf{3}$ will be published elsewhere). At such distance between the donor and the acceptor moieties, both Förster- and Dexter-types of RET may be enabled. ${ }^{17}$

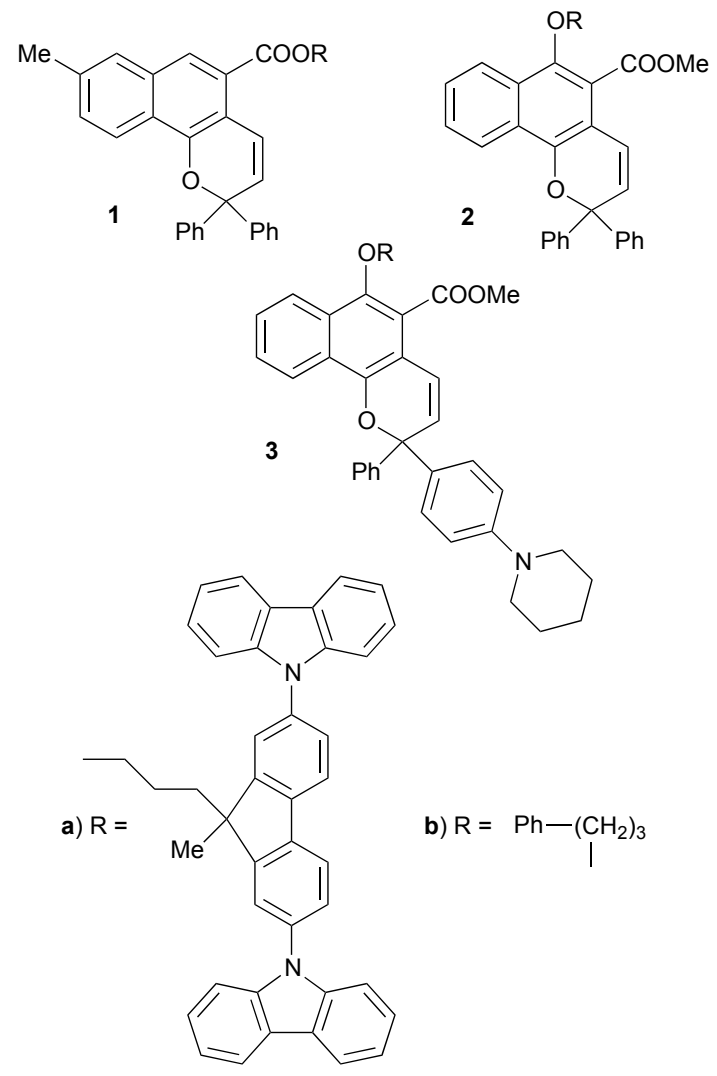

Fig. 1. Derivatives $\mathbf{1}-\mathbf{3}$ with the 2PA moiety (a-series) and model compound (b-series)

The structure variation $\mathbf{2}$ vs. 1 provides a shorter distance between the two moieties, whereas the variation 3 vs. 2 should give rise to a red shift in absorption of the respective colored form owing to the presence of the amino group in the para-position of one of the phenyl groups.

Fluorene derivative $7 a^{18}$ and the respective bromide $8 a$ and iodide 9a (Scheme 2) were used for the modifications of the photochromic units $4^{19}, 5^{20}$ and 6 (prepared by analogy to ${ }^{20}$ ) owing to the high fluorescence quantum yield and relatively large 2PA cross section of the respective 2,7bis(amino)fluorene derivatives ${ }^{21}$. The synthetic routes toward $\mathbf{1 - 3}$ are shown in Scheme 2. These compounds were purified by column chromatography and characterized by the NMR and HRM spectra. The best yields of derivatives $\mathbf{2}$ and $\mathbf{3}$ were achieved using iodides $\mathbf{9 a}, \mathbf{b}$.

Derivative 1a crystallizes out of acetonitrile solution as colorless crystals of two different shapes. The X-ray analysis ${ }^{\ddagger}$ showed that the rectangular prisms involve one molecule of acetonitrile per molecule of $\mathbf{1 a}$ (Fig. 2), while the hexagonal prisms are solvent free.
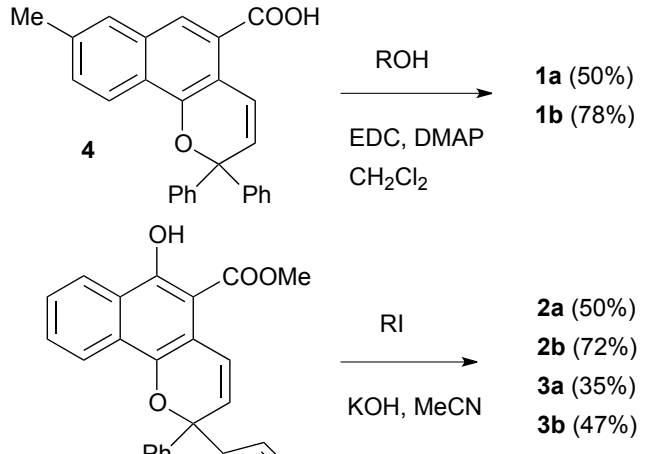

a) $\mathrm{R}=$

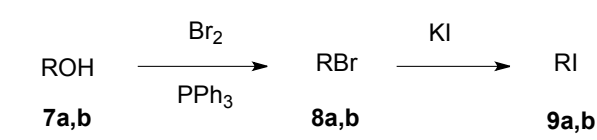

Scheme. 1. Synthesis of chromenes $\mathbf{1}-\mathbf{3}$ and precursors $\mathbf{7}$ - $\mathbf{9}$

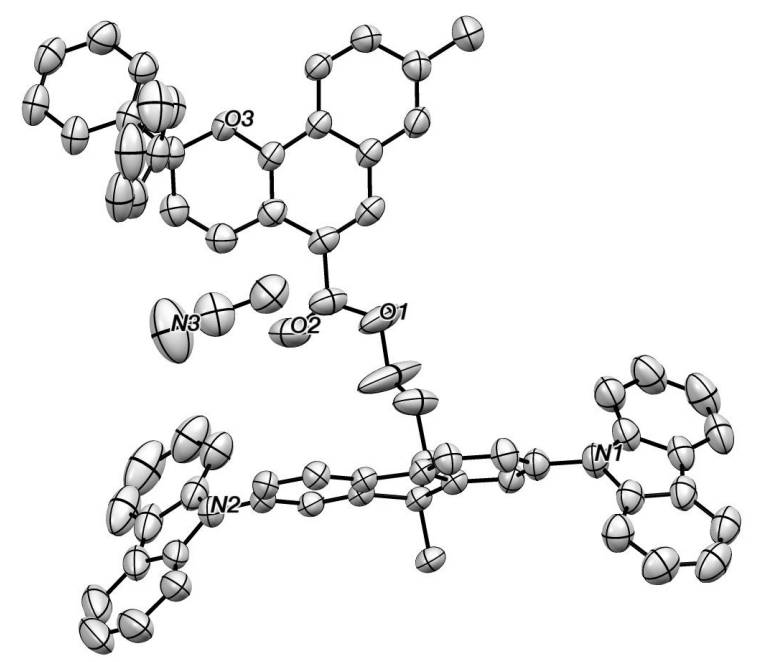

Fig. 2. ORTEP representation of the molecular structure of 1a with one molecule of acetonitrile (hydrogen atoms are omitted, thermal ellipsoids are presented at $50 \%$ of probability).

The molecular geometry of 1a in the crystals of both types is very similar and is characterized by the 'unfolded' conformation with the distance between the photochromic and 2PA moiety of about $7 \AA$, in contrast to the 'folded' configuration produced by the geometry optimization. There 
are several short intermolecular distances in the crystal lattice in both types of crystals that may constrain the molecule in this conformation.

The longest wavelength absorption bands of derivatives 1 3, a - series in methylene chloride are observed as shoulders between $370(\mathbf{2}, \mathbf{3})$ and $380 \mathrm{~nm}(\mathbf{1}),(\varepsilon$ about 10,000) on the strong absorption bands of the fluorene moiety $(340 \mathrm{~nm}, \varepsilon$ about 80,000), overlapping well with the fluorescence band of 7a (Fig. 3).
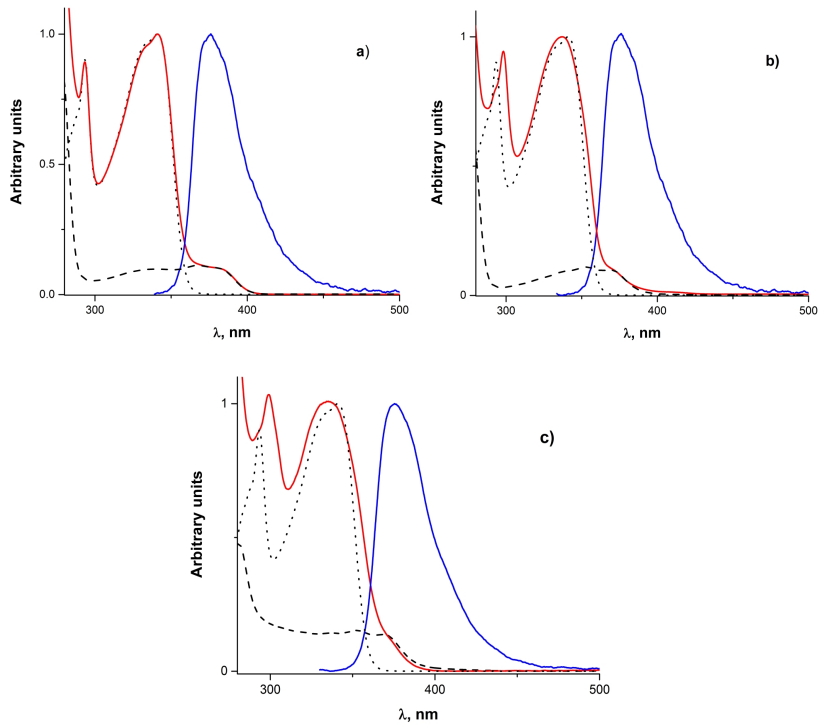

Fig. 3. Normalized absorption spectra in methylene chloride at $2 \times 10^{-5} \mathrm{M}$ : (a) 1 ; (b) 2 ; (c) 3. Red: a - series; dashed: $\mathbf{b}$ - series; dotted: $7 \mathbf{a}$; blue: normalized fluorescence of $7 \mathbf{a}$ $\left(\lambda_{\mathrm{ex}}=330 \mathrm{~nm}\right)$.

The absorption spectrum of 1a represents an exact sum of the spectra of $\mathbf{1 b}$ and $\mathbf{7 a}$ indicating the absence of electronic interaction between the photochromic and 2PA moieties. Minor deviations in the absorption band positions and shapes in the spectra of $\mathbf{2 a}$ and $\mathbf{3 a}$ may indicate the presence of weak through-space interaction between the two functional moieties. No concentration dependence of the absorption spectra within the range of $10^{-3}-10^{-6} \mathrm{M}$ was observed.

Whereas the dicarbazolyl fluorene precursor $7 \mathbf{a}$ is strongly fluorescent (the quantum yield $c a .80 \%$ ), derivative 1a exhibits only weak fluorescence (the quantum yield $c a .1 \%$ ) at about $380 \mathrm{~nm}$ and derivatives $\mathbf{2} \mathbf{a}$ and $\mathbf{3 a}$ are practically nonfluorescent. Such strong fluorescence quenching may indicate the occurrence of the efficient RET process. Irradiation of solutions of all six derivatives at 315,330 or $350 \mathrm{~nm}$ (1PA) brings about rapid coloration owing to the formation of the colored open forms of the photochromes as a mixture of isomers (Scheme 4, Fig. 4), yellow-orange for $\mathbf{1}$ and $\mathbf{2}$ and violet for 3. A hypsochromic shift of the colored forms generated at $330 \mathrm{~nm}$ from 3a is observed (Fig. 5a) during thermal discoloration owing to the different stabilities of the colored form isomers. Only derivatives 1a - 3a undergo coloration upon laser irradiation at $620 \mathrm{~nm}$ (2PA)(Fig. 5b).

Increasing polarity of the solvent (methylene chloride vs. toluene) brings about small shifts in the position of the absorption band maxima of the colored forms. The species generated by irradiation of $\mathbf{1 a}$ and $\mathbf{2 a}$ at $315,330,350$ (1PA) and 620 (2PA) nm show similar absorption spectra (Fig. 5b).<smiles>[R16]OC(=O)c1c2c(c([X])c3cc([R])ccc13)C=CC(c1ccc([R])cc1)(c1ccc([R])cc1)O2</smiles><smiles>[R]OC(=O)C1=C([X])c2cc([R])ccc2C(=O)/C1=C/C=C(\c1ccc([R])cc1)c1ccc([18OH])cc1</smiles>

+ isomers

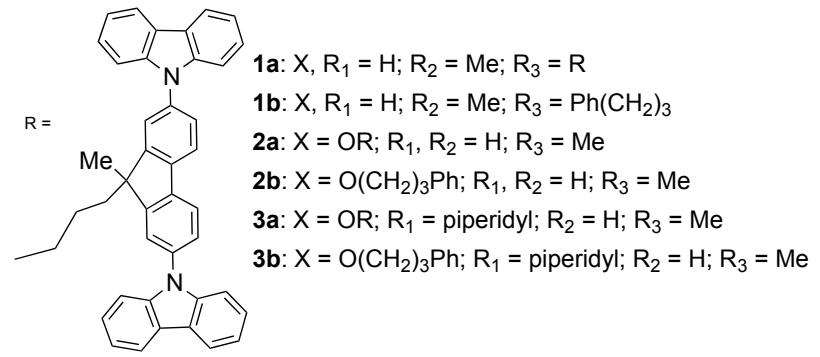

Scheme 2. Photochromism of derivatives 1 - 3
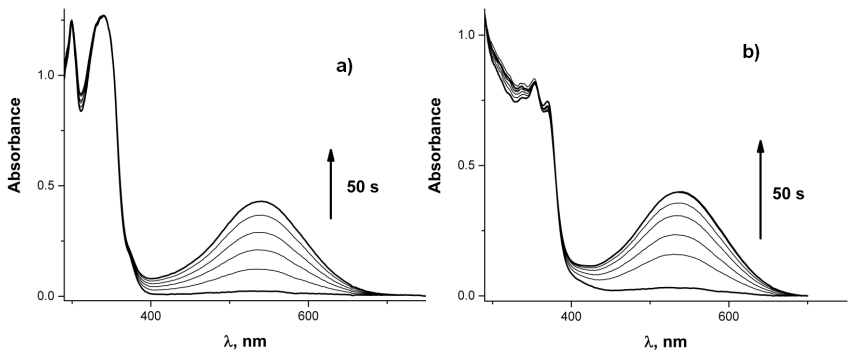

Fig.4. Irradiation in toluene at $330 \mathrm{~nm}$; (a) $3 \mathbf{a}\left(1.2 \times 10^{-5} \mathrm{M}\right)$; (b) $\mathbf{3 b}\left(10^{-4} \mathrm{M}\right)$.
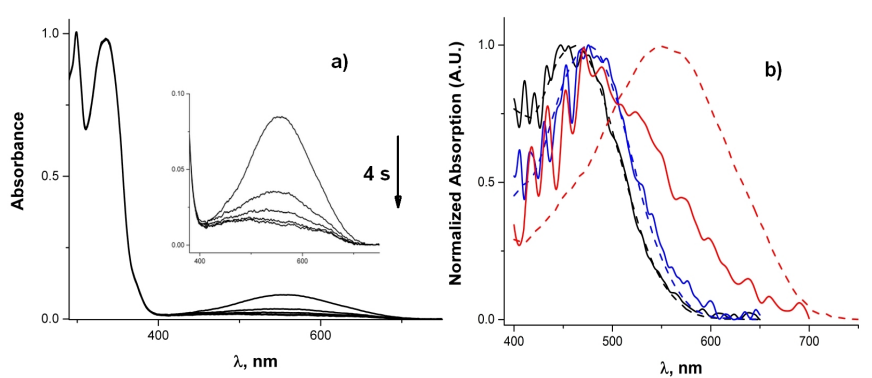

Fig. 5. (a) Thermal discoloration of $\mathbf{3 a}$ irradiated at $330 \mathrm{~nm}$ in methylene chloride; (b) UV-Vis absorption spectra of 1a (black), 2a (blue) and 3a (red) irradiated at $620 \mathrm{~nm}$ (solid lines) and $330 \mathrm{~nm}$ (dashed lines) in methylene chloride. 
Table 1. Absorption maxima and the half-life times of the colored open isomers generated from $1-3$ at $330 \mathrm{~nm}(1 \mathrm{PA})$ and $620 \mathrm{~nm}(2 \mathrm{PA})$.

\begin{tabular}{lllll}
\hline Entry & $\lambda_{\max }(\mathrm{nm})^{\mathrm{a}}$ & $\mathrm{t}_{1 / 2}(\mathrm{~s})^{\mathrm{a}}$ & $\lambda_{\max }(\mathrm{nm})^{\mathrm{b}}$ & $\mathrm{t}_{1 / 2}(\mathrm{~s})^{\mathrm{b}}$ \\
1a & 462 & 17 & $464(465)^{\mathrm{c}}$ & 35 \\
1b & 475 & 77 & 462 & 41 \\
2a & 472 & 77 & $475(475)^{\mathrm{c}}$ & 173 \\
2b & 475 & 178 & 478 & 173 \\
3a & 540 & 43 & $556(480)^{\mathrm{c}}$ & 2 \\
3b & 544 & 46 & 550 & 23 \\
& & & \\
a & in toluene, ${ }^{\mathrm{b}}$ in methylene chloride, ${ }^{\mathrm{c}}$ irradiated at $620 \mathrm{~nm}$. & \\
\hline
\end{tabular}

The exception is $\mathbf{3 a}$ : irradiation at $315-350 \mathrm{~nm}$ gives rise to a very broad absorption band covering all visible range red shifted by $16 \mathrm{~nm}$ in methylene chloride compared to toluene. The spectrum of femtosecond pulse at irradiation $620 \mathrm{~nm}$ overlaps with the absorption of the colored isomers and gives rise to the band shape distortion owing to photo-discoloration of the longer wavelength absorbing isomers (Fig. 5b). The color fading observed for this derivative is very rapid: the half-life time $t_{1 / 2}$ in methylene chloride is just 2 seconds.

The half-life times of other derivatives vary in a nonsystematic way and the variations can stem from steric rather than from the electronic factors. This phenomenon was observed also in the case of other chromene derivatives. ${ }^{22}$

Derivatives $\mathbf{1 b}-\mathbf{3 b}$ do not exhibit coloration under $620 \mathrm{~nm}$ laser irradiation. A more detailed quantitative optical characterization of these compounds, including nonlinear properties, is currently under way.

\section{Conclusions}

The non-conjugative tethering of the relatively bulky 2PA moiety to the photochromic $2 \mathrm{H}$-benzo[h]chromenes (the derivatives of a-series) does not negatively affect their performance as photochromic materials as compared to the derivatives of $\mathbf{b}$-series. All derivatives of the a-series undergo coloration under femtosecond laser irradiation at $620 \mathrm{~nm}$ and quenching of fluorescence from the 2PA moiety corroborates the occurrence of the efficient RET process, whose exact nature still has to be established.

\section{Notes and references}

¥ Single crystals of 1a were grown from acetonitrile. X-ray crystallography data were collected on a Bruker-Nonius KappaCCD diffractometer with CCD detector using MoK $_{\text {radiation }}(\lambda=0.71073 \AA$ ). Crystallographic data for the structures reported in this paper have been deposited with the Cambridge Crystallographic Data Centre: 1a involving one acetonitrile molecule: CCDC 1033558; solvent-free crystals: CCDC 1033559.

1 J. C. Crano, R. J. Guglielmetti, Organic Photochromic and Thermochromic Compounds, Vol. 1, New York: Plenum Press; 1999.

2 D. A. Parthenopoulos, P. M. Rentzepis, Science, 1989, 245, 843; S. Kawata, Y. Kawata, Chem. Rev., 2000, 100, 1777.
3 D. J. Hagan, Optical limiting. In: M. Bass, series editor. Handbook of optics, $3^{\text {rd }}$ Ed, New York: McGraw-Hill; 2009, vol IV, p. 13.1; J. Oberlé, L. Bramerie, G. Jonusauskas, C. Rullière, Opt. Commun., 1999, 169, 325; M. P. Joshi, J. Swiatkiewicz, P. N. Prasad, B. A. Reinhardt, R. Kannan, Optics Letters, 1998, 23, 1742.

4 S. Yagai, A. Kitamura, Chem. Soc. Rev., 2008, 37, 1520.

5 G. Berkovic, V. Krongauz, V. Weiss, Chem. Rev. 2000, 100, 1741.

6 J. Harada, R. Nakajima, K. Ogava, J. Am. Chem. Soc., 2008, 130, 7085.

7 Y. Tsuboi, R. Shimizu, T. Shoji, N. Kitamura, J. Am. Chem. Soc., 2009, 131, 12623.

8 C. Beyer, H.-A. Wagenknecht, Synlett., 2010, 1371; I. A. Mikhailov, K. D. Belfield, A. E. Masunov, J. Phys. Chem., 2009, 113, 7080.

9 J. T. Dy, R. Maeda, Y. Nagatsuka, K. Ogava, K. Kamada, K. Ohta, Y. Kobuke, Chem. Commun., 2007, 5170; K. Ogava, Y. Kobuke, Org. Biomol. Chem., 2009, 7, 2241; K. Ogava, J. Dy, R. Maeda, Y. Nagatsuka, K. Kamada, Y. Kobuke, J. Porphyrins Phthalocyanines, 2013, 17, 821.

10 R. D. Breukers, S. Janssen, S. G. Raymond, M. D. H. Bhuiyan, A. J. Kay, Dyes and Pigments, 2015, 112, 17.

11 K. Ogava, Appl. Sci., 2014, 4, 1.

12 R. Gvishi, Z. Kotler, G. Berkovic, P. Krief, M. Sigalov, L. Shapiro, D. Huppert, V. Khodorkovsky, V. Lokshin, A. Samat, Proc. SPIE Int. Soc. Opt. Eng., 2005, 5724, 13.

13 K. D. Belfield, M. V. Bondar, C. C. Corredor, F. E. Hernandez, O. V. Przhonska, S. Yao, Chem. Phys. Chem., 2006, 7, 2514.

14 R. Métivier, S. Badré, R. Méallet-Renault, P. Yu, R. B. Pansu, K. Nakatani, J. Phys. Chem. C, 2009, 113, 11916; C. C. Corredor, Z.-L. Huang, K. D. Belfield, A. R. Morales, M. V. Bondar, Chem. Mater., 2007, 19, 5165.

15 K. Mutoh, M. Sliwa, J. Abe, J. Phys. Chem. C, 2013, 117, 4808; E. Deniz, M. Battal, J. Cusido, S. Sortino, F. M. Raymo, Phys. Chem. Chem. Phys., 2012, 14, 10300.

16 S. Saita, T. Yamaguchi, T. Kavai, M. Irie, Chem. Phys. Chem., 2005, 6, 2300.

17 H.-J. Xu, A. Bonnot, P.-L. Karsenti, A. Langlois, M. Abdelhameed, J.-M. Barbe, C. P. Gros, P. D. Harvey, Dalton Trans., 2014, 43, 8219; J. R. Winkler, Science, 2013, 339, 1530.

18 J. Y. Cho, B. Domercq, S. Barlow, K. Yu. Suponitsky, J. Li, T. V. Timofeeva, S. Jones, L. E. Hayden, A. Kimyonok, C. R. South, M. Weck, B. Kippelen, S. R. Marder, Organomet., 2007, 26, 4816.

19 N. Malic, J. A. Campbell, A. S. Ali, M. York, A. D'Souza, R. A. Evans, Macromolecules, 2010, 43, 8488.

20 A. Kumar, B. van Gemert, D. B. Knowles, US Patent 5,458,814; Oct. 17, 1995.

21 K. D. Belfield, K. J. Shafer, W. Mourad, B. A. Reinhardt, J. Org. Chem., 2000, 65, 4475.

22 J. D. Hepworth, B. M. Heron, Photochromic naphthopyrans. In: S. H. Kim, editor. Functional dyes. Amsterdam: Elsevier; 2006. p. 85. 